${ }^{36} \mathrm{~F}$. LuCAs, "Résolution électrique des équations algébriques," loc. cit., p. 268-270.

${ }^{37} \mathrm{~F}$. LuCAs, "Détermination électrique des lignes isodynamiques d'un polynôme quelconque," loc. cit., p. 587-589.

${ }^{38}$ F. LUCAS, "Résolution immédiate des équations au moyen de l'électricité," loc. cit., p. 645-648.

${ }^{39} \mathrm{~F}$. Lucas, "Résolution des équations par l'électricité," loc, cit., p. 1072-1074.

${ }^{40} \mathrm{~F}$. LuCAS, "Résolution électromagnétique des équations," Acad. d. Sci., Paris, Comptes Rendus, v. 111, 1890, p. 965-967.

${ }^{11}$ o J. C. JAmin, Cours de Physique de l'École Polytechnique, Paris, v. 4, fourth ed. by E. Bouty, 1888-91, p. 170, figs. 2-3. Also P. E. A. GuEbHARD, J. d. Physique, s. 2, v. 1, 1882 , p. 205.

42 L. KANN, "Zur mechanischen Auflösung von Gleichungen. Eine elektrische GleichungsMaschine," Z. Math. Phys., v. 48, 1902, p. 266-272.

${ }^{43} \mathrm{~A}$. RusSELL \& A. WRIGHT, "The Arthur Wright electrical device for evaluating formulae and solving equations," Phil. Mag., s. 6, v. 18, 1909, p. 291-308.

${ }^{44} \mathrm{~A}$. Russell \& J. N. Alty, "An electromagnetic method of studying the theory of and solving algebraical equations of any degree," Phil. Mag., s. 6, v. 18, 1909, p. 802-811.

${ }^{45}$ R. R. M. MALlock, "An electrical calculating machine," R. So. London, Proc., v. $140 \mathrm{~A}, 1933$, p. $457-483$.

${ }^{46} \mathrm{H}$. C. HART \& I. Travis, "Mechanical solution of algebraic equations," Franklin Inst., $J .$, v. 225,1938 , p. 63-72. 262-264.

${ }^{77}$ H. D. Green, "Square root extractor," Rev. Sci. Instruments, n.s., v. 11, 1940, p.

${ }^{48}$ R. L. Dietzold, "The isograph-a mechanical root-finder," Bell Laboratories Record, v. 16,1937, p. $130-134$.

49 R. O. MERCNER, "The mechanism of the isograph," loc. cit., p. 135-140.

so "Mechanical aids to mathematics: Isograph for the solution of complex polynomials," Electronics, v. 11, Feb., 1938, p. 54.

s1 S. L. BRown, "A mechanical harmonic synthesizer-analyzer," Franklin Inst., J., v. 228, 1939, p. 675-694; reviewed in $M T A C$, p. 127.

52 S. L. BRown \& L. L. WheEler, "A mechanical method for graphical solution of polynomials," Franklin Inst., J., v. 231, 1941, p. 223-243; reviewed in MTAC, p. 128.

${ }_{53}$ D. Baxandall, "Calculating machines," Encyclopadia Britannica, fourteenth ed., v. 4, 1929, p. 551-553. Note bibliography at end.

${ }_{54}$ P. Werkmeister, "Die Auflösung eines Systems linearer Gleichungen mit Hilfe der Rechenmaschine 'Hamann-Automat'," Z. f. Instrumententechnik, v. 51, 1931, p. 490.

${ }_{55}$ S. Lilley, "Mathematical machines," Nature, v. 149, 1942, p. 462-465; reviewed in $M A T C$, p. 61 .

${ }_{56} \mathrm{~V}$. BusH, "The differential analyzer. A new machine for solving differential equations," Franklin Inst., J., v. 212, 1931, p. 447-488.

References to unreviewed items are as follows:

${ }^{67} \mathrm{G}$. Rosén, "Eine elektromechanische 'Gleichungswage,"' Elektrotechn. Z., v. 50, 1929, p. 1726-1727.

s8 G. Revessi, "Verso soluzioni meccaniche ed elettriche dei sistemi di equazioni lineari," L'Elettrotecnica, v. 12, 1925, p. 550-553.

\title{
Zeros of Certain Bessel Functions of Fractional Order
}

The following tables contain the zeros of $J_{\nu}(x)$ for $x \leqslant 25$, where $\nu= \pm 1 / 3, \pm 2 / 3, \pm 1 / 4, \pm 3 / 4$. These zeros were obtained by inverse interpolation in a thirteen-place manuscript of these functions, computed by the NYMTP. The accuracy of the zeros to $10 \mathrm{D}$ is guaranteed, and the two additional places have a high probability of being correct.

$j+1 / 4, *$

2.780887723995

5.906142698843

9.042383663583

12.181341528955

15.321369826012

18.461927245689

21.602784448913

$24.743827796128(24.740)$ $j-1 / 4,0$

2.006299671790

5.123062742746

8.257951175642

11.396467696987

14.536299884338

17.676753586847

20.817549422232

23.958553495286 (23.955) 
3.4910083741

3.491008374108
6.652635523122

9.801612359140

12.947034889139

16.090969528199

19.234141760482

$22.376871574816(22.384)$

$j_{+1 / 8,0}$

2.902586248417

6.032747057266

9.170506669464

12.310193771645

15.450648967817

18.591486336181

21.732541161747

24.873731422806 (24.871)

$$
j_{+2 / 8,0}
$$

3.375610652694

6.530255936513

9.676580635238

12.820608678466

15.963683880906

19.106273504592

22.248582393360 (22.253) $j_{-3 / 4,0}$

1.058508259404

4.284053812724

7.440454404005

10.588179148660

13.733118450574

16.876817513875

20.019857583986

23.162505934075 (23.169)

$j_{-1 / 8, \bullet}$
1.866350858874
4.987853231435
8.124265381940
11.263514825428
14.403775880136
17.544510655721
20.685504806124

23.82665 $6247057(23.824)$

$j_{-2 / 8, \bullet}$
1.243046259619
4.429120677699
7.579458446530
10.724746924499
13.868374583331
17.011254500133
20.153734537151
$23.295975867060(23.300)$

For $x>25$, ten or more decimal places in the zeros may be obtained from the well-known formula (five terms) for the roots of Bessel functions, given below; see, for example, G. N. WATson, Treatise on the Theory of Bessel Functions, 1922 and 1944, p. 506; the sixth term was supplied by W. G. Bickley, ${ }^{1}$ Phil. Mag., s. 7, v. 34, 1943, p. 40 :

$$
\begin{gathered}
j_{r, 8}=\beta-\frac{\mu-1}{2^{3} \beta}-\frac{(\mu-1)(7 \mu-31)}{3 \cdot 2^{7} \cdot \beta^{3}}-\frac{(\mu-1)\left(83 \mu^{2}-982 \mu+3779\right)}{15 \cdot 2^{10} \cdot \beta^{5}} \\
-\frac{(\mu-1)\left(6949 \mu^{3}-153855 \mu^{2}+1585743 \mu-6277237\right)}{105 \cdot 2^{15} \cdot \beta^{7}} \\
-\frac{(\mu-1)\left(70197 \mu^{4}-2479316 \mu^{3}+48010494 \mu^{2}\right.}{315 \cdot 2^{18} \cdot \beta^{9}}
\end{gathered}
$$

where $\beta=\left(s+\frac{1}{2} \nu-\frac{1}{4}\right) \pi ; \mu=4 \nu^{2}$. The first five terms of the above expression will yield at least 10 decimals for roots greater than those given here. The values of $\beta$ corresponding to the highest roots given here are noted in parenthesis; it is apparent that for $x$ close to $25, \beta$ approximates the root to two decimals at least.

The author desires to express his appreciation of assistance rendered by several members of the NYMTP in checking these values.

\section{NYMTP}

Milton Abramowitz

1 It may be noted that in Bickley's article the fifth term of the formula has an erroneous number 6277327 , for 6277237 . 